\title{
EXCHANGE TRANSFUSION IN NEONATAL SEPSIS DOSE NOT REDUCES OVERALL MORTALITY
}

Uday Rajput ${ }^{1}$, L.S. Deshmukh²

\section{HOW TO CITE THIS ARTICLE:}

Uday Rajput, LS Deshmukh. "Exchange transfusion in neonatal sepsis dose not reduces ov erall mortality". Journal of Evolution of Medical and Dental Sciences 2013; Vol. 2, Issue 43, October 28; Page: 8297-8301.

\begin{abstract}
OBJECTIVES: To evaluate the role of exchange transfusion in severe neonatal sepsis. DESIGN: Retrospective cohort study. SETTING: Neonatal intensive care unit of teaching hospital. SUBJECTS \& METHOD: Retrospective cohort study was carried out from June 2010 to May 2011. Thirty babies who developed severe sepsis (Sclerema) and who underwent double volume exchange transfusion primarily for sepsis, were included in the study and were compared with matched controls who did not receive exchange transfusion. RESULTS: The overall mortality rate in study group was $49 \%$ as compared to $62 \%$ in the controls. However the difference was not statistically significant. The duration of hospital stay was longer in the study group (45 Vs 29 days) ( $<<0.001$ ). Exchange transfusion did not make any different to the organism specific mortality. No clinically significant complications were observed with exchange transfusion. CONCLUSIONS: Exchange transfusion does not alter the mortality in the babies with severe sepsis.
\end{abstract}

KEY WORDS: Sclerema, Severe sepsis, Exchange transfusion.

INTRODUCTION: Neonatal sepsis is a frequent and serious event, which threatens survival during the first four weeks of life. In developing countries, public hospitals face the major burden of this problem. Public hospitals many times face the paucity of higher antibiotics, in addition, septicemia requires lot of supportive measures and intensive therapy leading to increase the length of NICU stay. All above factors add to increased neonatal care cost and poor outcome.

Exchange transfusion has been tried to improve the immediate outcome in severely septicemic babies ${ }^{1-9}$. However, there are very few studies of role of exchange transfusion in sepsis particularly in developing countries.6,7,8. Considering the possible usefulness of exchange transfusion in severely septicemic babies, present study was undertaken.

SUBJECTS AND METHODS: A retrospective cohort study was done to evaluate the role of exchange transfusion in severe neonatal sepsis at Neonatal Intensive Care Unit of Government Medical College and Hospital, Aurangabad during June 2010 to May 2011.

Thirty septicemic neonates who were critically ill (Sclerema), underwent exchange transfusion.

They were compared with age-matched controls, who were critically ill (Sclerema) but did not undergo exchange transfusion. Babies having clinical features of severe sepsis (sclerema), irrespective of growth on blood culture were included in the study.

Babies requiring exchange transfusion for hyperbilirubinemia were excluded.

A double volume exchange transfusion with cross-matched adult whole blood was done. The anticoagulant used in donor blood was CPD and was negative for HbsAg, HCV, MP, VDRL and HIV.

Pre and Post Exchange blood culture, blood sugar and hemoglobin were done in each case. Vitals of babies were monitored throughout the procedure. Rest of the management was similar in 
both groups. Primary outcome measured was effect on neonatal mortality, secondary outcome measures included duration of hospital stay and organism specific mortality.

Statistical analysis was done by applying Fischer's Exact Test, 'p' value $<0.05$ was taken as statistically significant.

RESULTS: Thirty neonates who underwent exchange transfusion for severe sepsis (sclerema) were included in the study and compared with 30 babies with severe sepsis (sclerema) who did not received exchange transfusion. The clinical profile in study and control group was comparable with regards to age, sex, gestational age and intrauterine growth (Refer Table - I).

Clinical features were comparable in both groups, the most common manifestation observed being fever (Refer Table - II).

Sixty percent of exchange transfusions were carried out from $3^{\text {rd }}$ to $7^{\text {th }}$ day of life.

There were overall 22 bacterial isolate (10 in control and 12 in study group) giving a overall culture positivity of $36.66 \%$ (Refer Table - III). Commonest bacterial isolate was, E. coli - 54\%, Staphylococcus aureus $-31.81 \%$ and Klebsiella - 13.63\% respectively (Refer Table - IV). The rate of culture positivity was comparable in both groups.

Overall morality in study group was $49 \%$ as compared to $62 \%$ in matched controls, which was statistically not significant ( $\mathrm{p}=0.2$, Fischer's Exact test).

Mortality rate was higher in preterm babies (55\%) as compared to term babies (30\%). However, there was no significant difference on comparison. ( $p=0.25, p=0.5$ respectively, Fischer's Exact test).

The gestational age wise mortality was comparable in both the groups. The overall mortality was highest between the 28 to 30 weeks, but was similar in two groups (83.67\%) (Refer Table - V).

No significant complications related to Exchange Transfusion were observed.

DISCUSSION: Incomplete development of host defense system of neonate is largely responsible for the high neonatal mortality in sepsis. ${ }^{1}$ IgA, IgM and C3 are not transferred transplacentally. Transfer of IgG occurs progressively, particularly after 20 weeks of gestation and levels are low in premature infants. Various authors have attempted Exchange transfusion as a treatment modality for severe septicemia. ${ }^{1-9}$

In the present study, the percentage mortality was less in study group. However the difference was not statistically significant.

Tollner et al studied 22 newborn who received exchange transfusion for sepsis. They showed impressive clinical improvement following exchange transfusion and decrease mortality. ${ }^{3}$ Dalvi et al studied 53 neonates for unresponsive sepsis treated with therapeutic exchange transfusion and showed overall survival of $77.4 \%$. However no controls were taken. ${ }^{4}$ Another study showed improved survival in septicemic neonate (54\% Vs 18\% in controls). ${ }^{5}$

Following exchange transfusion, the survival was highest in the term babies (70\%). However, it was comparable with control group (60\%) ( $\mathrm{p}=0.5$, Fischer's Exact test). The mortality was highest between 28-30 weeks (83.67\%) but was not significant. Most of the babies who were below 30 weeks had severe respiratory distress syndrome, hence the mortality was considerably higher in this group. 
In our study, however contrary to the expectation, the mean duration of hospital stay was longer in cases as compared to controls $(\mathrm{p}<0.001$, Unpaired ' $\mathrm{t}$ ' test). This could have been because babies in study group requiring longer duration of antibiotics and also early deaths in controls.

There were no complications related to exchange transfusion.

Exchange transfusion provides immunological components leading to increase in levels of IgA, IgG and IgM. ${ }^{6}$ In addition, it may provide other advantages like removal of bacteria and bacterial toxins, increase in pool of neutrophils, improvement in perfusion and tissue oxygenation and decrease in haemorrhagic complications. ${ }^{7}$

In conclusion, though the exchange transfusion as an immunomodulatory ther apy for severe sepsis in neonate is an alternative to costly immunomodulatory drugs, it does not improve the survival. However, further randomized control trials for the role of exchange transfusion in severe sepsis are essential.

\section{KEY MESSAGES:}

- The overall mortality in severe septicemic babies is very high

- Exchange transfusion for severe sepsis does not improve the survival irrespective of gestational age.

- $\quad$ No significant complications are observed with exchange transfusion.

CONTRIBUTORS: LSD was involved in designing the study and preparation of the manuscript. UCR was involved in conduction of study and manuscript writing.

Funding - None

Competing interests - None stated.

ACKNOWLEDGEMENT: The authors thanks Dean, Government Medical College and Hospital, Aurangabad for allowing us to conduct the study.

\section{REFERENCES:}

1) Yoder MC, Polin RA. Immunotherapy of neonatal septicemia. Pediatr Clin North Am 1986; 33:481-501.

2) Vain NE, Mazlumian JR, Swarner OW, Cha CC. Role of exchange transfusion in the treatment of severe septicemia. Pediatrics 1980; 66(5):693-7.

3) Tollner U, Pohlandt F, Heinze F, Henrich I. Treatment of septicemia in the newborn infant : Choice of initial antimicrobial drugs and the role of exchange transfusion. Acta Pediatr Scand 1977; 66(5):605-10.

4) Dlavi R, Rao S, Rangnekar J, Fernandez A. Exchange transfusions in neonatal sepsis. Indian Pediatr 1991; 28(1):39-43.

5) Belohradsky BH, Simon G, Spier JM, Ross R, Marger W. The immunoglobulin state of the neonate following surgery: Consequences for immunotherapy of neonatal septicemia. Progr Pediatr Surg 1979; 13:39-51.

6) Gunes T, Koklu E, Buyukkayhan D et al. Exchange transfusion or intravenous immunoglobulin therapy as an adjunct to antibiotics for neonatal sepsis in developing countries: a pilot study. Ann Trop Pediatr. Int Child Health 2006; 26(1):39-42. 
7) Sadana S, Mathur NB, Thakur A. Exchange transfusion in septic neonates with sclerema: Effect on immunoglobulin and complement levels. Indian Pediatr 1997; 34(1):20-5.

8) Novoyanan I, Mitter A, Gujral VY. A comparative study on the value of exchange transfusion in the management of severe neonatal septicemia with sclerema. Indian J Pediatr 1982; 49(399):519-23.

9) Xanthou M, Xypolyta A, Anagnostakis D, Economou-Mavrou C, Matasaniotis N. Exchange transfusion in severe neonatal infection with sclerema. Arch Dis Child 1975; 50(II):901-02.

\section{TABLES}

\begin{tabular}{|l|c|c|}
\hline \multicolumn{1}{|c|}{ Parameters } & Control Group & Study Group \\
\hline & $(\mathrm{n}=30)$ & $(\mathrm{n}=30)$ \\
\hline Home delivery & $22(73.33 \%)$ & $22(73.33 \%)$ \\
\hline M:F & $1.7: 1$ & $1.7: 1$ \\
\hline Mean gestational age & $33 \mathrm{wks}$ & $33 \mathrm{wks}$ \\
\hline Percentage of preterm & $20(66.66 \%)$ & $20(66.66 \%)$ \\
\hline SGA babies & $06(20.00 \%)$ & $06(20.00 \%)$ \\
\hline Mean weight (Kg) & 1.63 & 1.68 \\
\hline Mean duration of hospital stay (Days) & 29 & 45 \\
\hline
\end{tabular}

Table - 1: Population characteristics of study and control group

$\left({ }^{*} \mathrm{P}<0.001\right.$, unpaired' $\mathrm{t}$ ' test $)$

\begin{tabular}{|l|c|c|}
\hline Clinical feature & $\begin{array}{c}\text { Control Group } \\
(\mathrm{n}=30)\end{array}$ & $\begin{array}{c}\text { Study Group } \\
(\mathrm{n}=30)\end{array}$ \\
\hline Fever & 29 & 29 \\
\hline Feeding difficulty & 26 & 25 \\
\hline Vomiting & 05 & 09 \\
\hline Jaundice & 30 & 30 \\
\hline Convulsions & 09 & 11 \\
\hline Lethargy & 23 & 24 \\
\hline
\end{tabular}

Table - 2: Clinical features of study groups and controls

\begin{tabular}{|c|c|c|c|c|c|}
\hline \multirow{2}{*}{ Culture } & \multicolumn{2}{|c|}{ Control Group } & \multicolumn{2}{c|}{ Study Group } & \multirow{2}{*}{ 'p' value* } \\
\cline { 2 - 5 } & Cases & Mortality (\%) & Cases & Mortality (\%) & \\
\hline Positite & 10 & $06(66.67 \%)$ & 12 & $08(66.67 \%)$ & $\mathrm{P}=0.2$ \\
\hline Sterile & 20 & $06(30.00 \%)$ & 18 & $05(27.78 \%)$ & $\mathrm{P}=0.01$ \\
\hline Total & 30 & $12(40.00 \%)$ & 30 & $13(43.33 \%)$ & $\mathrm{P}=0.5$ \\
\hline
\end{tabular}

Table -3: Outcome in study and control group based on culture positivity

(*Fischer's Exact test) 


\begin{tabular}{|c|c|c|c|c|}
\hline \multirow{2}{*}{ Organisms } & \multicolumn{2}{|c|}{ Control Group } & \multicolumn{2}{c|}{ Study Group } \\
\cline { 2 - 5 } & Cases & Mortality (\%) & Cases & Mortality (\%) \\
\hline E. coli & 05 & $03(60.00 \%)$ & 07 & $04(57.80 \%)$ \\
\hline Staph. Aureus & 03 & $01(44.44 \%)$ & 04 & $03(75.00 \%)$ \\
\hline Klebsiella & 02 & $02(100 \%)$ & 01 & $01(100 \%)$ \\
\hline Total $^{*}$ & 10 & $06(60.00 \%)$ & 12 & $08(66.66 \%)$ \\
\hline
\end{tabular}

Table - 4: Bacterial isolates in controls and study groups

(* $\mathrm{p}=0.54$, Fischer's Exact test)

\begin{tabular}{|c|c|c|c|c|c|}
\hline \multirow{2}{*}{$\begin{array}{c}\text { Gestational age } \\
\text { (Weeks) }\end{array}$} & \multicolumn{2}{|c|}{ Control Group } & \multicolumn{2}{c|}{ Study Group } & \multirow{2}{*}{ 'p' value* } \\
\cline { 2 - 5 } & Cases & Mortality (\%) & Cases & Mortality (\%) & \\
\hline $28-30$ & 06 & $05(83.67 \%)$ & 06 & $05(83.67 \%)$ & -- \\
\hline $32-34$ & 09 & $06(66.67 \%)$ & 09 & $04(44.50 \%)$ & $\mathrm{p}=0.5$ \\
\hline $34-37$ & 05 & $03(60.00 \%)$ & 05 & $02(40.00 \%)$ & $\mathrm{p}=0.5$ \\
\hline$>37$ & 10 & $04(40.00 \%)$ & 10 & $03(30.00 \%)$ & $\mathrm{p}=0.5$ \\
\hline Total & 30 & $18(60.00 \%)$ & 30 & $14(46.00 \%)$ & $\mathrm{P}=0.2$ \\
\hline
\end{tabular}

(*Fischer's Exact test)

\section{AUTHORS:}

1. Uday Rajput

2. L.S. Deshmukh

\section{PARTI CULARS OF CONTRIBUTORS:}

1. Assistant Professor, Department of Pediatrics, Neonatal Intensive Care Unit of Government Medical College and Hos pital, Aurangabad.

2. Professor In-Charge, Department of Neonatology, Neonatal Unit, Neonatal Intensive Care Unit of Government Medical College and Hospital, Aurangabad.

\section{NAME ADDRESS EMAIL ID OF THE CORRESPONDING AUTHOR:}

Dr. Uday Rajput, c/o Dr. Mrs Rajput, Prof \& Head, OBGY Dept., Wanless Mission Hospital, Miraj - 416410, Maharashtra.

Email - druday rajput@gmail.com

Date of Submission: 15/10/2013.

Date of Peer Review: 16/10/2013.

Date of Acceptance: 22/10/2013.

Date of Publishing: 23/10/2013 